\title{
La investigación sobre el conocimiento profesional de los profesores de primaria en ciencias y el conocimiento escolar: una revisión (parte II)
}

Martínez Rivera Carmen Alicia', Jirón Popova Mirna ${ }^{2}$

Categoría 2. Trabajo de investigación.

\section{Resumen}

En esta ponencia presentamos un segundo avance del estado del arte, resultado del proyecto de investigación: "El conocimiento profesional de los profesores de ciencias sobre el conocimiento escolar: dos estudios de caso en el Distrito Capital". Aquí recogemos las posturas que se exponen en los trabajos académicos presentados en el $\vee$ Congreso Internacional sobre Formación de Profesores en Ciencias (Bogotá, Colombia, 2011), los cuales analizamos a la luz de las siguientes categorías propuestas en esta investigación: contenidos escolares; fuentes y criterios de selección de los contenidos escolares; referentes del conocimiento escolar; y criterios de validez.

\section{Palabras claves}

Conocimiento profesional, estado del arte, conocimiento escolar, educación primaria, enseñanza de las ciencias

\section{Objetivo}

Si bien la investigación en la que se enmarca este avance, busca caracterizar el conocimiento profesional sobre el conocimiento escolar, de profesores(as) de primaria que enseñan ciencias; en esta ponencia en particular, pretendemos caracterizar algunos antecedentes investigativos a partir del análisis de las categorías de interés que sustentan nuestra investigación, dando así continuidad a la parte I de la revisión presentada en Martínez y Jirón (2012).

\footnotetext{
1 Universidad Distrital Francisco José de Caldas, camartinezr@udistrital.edu.co

2 Universidad Distrital Francisco José de Caldas, mjiron@udistrital.edu.co
} 
Revista Tecné, Episteme y Didaxis: TED. Año 2014, Número Extraordinario. ISSN Impreso: 0121-3814, ISSN web: 2323-0126

Memorias, Sexto Congreso Internacional sobre Formación de Profesores de Ciencias. 08 al 10 de octubre de 2014, Bogotá

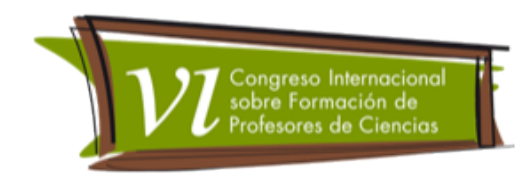

\section{Marco teórico}

El conocimiento de los profesores(as) de ciencias es un conocimiento particular que se identifica por ser: práctico, integrador, profesionalizado, evolutivo y procesual; que reconoce la complejidad y singularidad de la escuela. Hay que señalar que el conocimiento profesional y el conocimiento escolar del profesor(a), son dos conocimientos epistemológicamente diferenciados entre sí y de los conocimientos disciplinar y cotidiano (Porlán y Rivero, 1998). Además estos conocimientos se conciben como una constante reformulación desde visiones simples hacia visiones más complejas -resultado de procesos constructivos y evolutivos-, que buscan centrarse en problemas que se consideren relevantes para la práctica educativa.

Reformulación que se constituye en hipótesis de progresión, desde la que se consideran los siguientes niveles: Nivel 1- tradicional, basado en aspectos conceptuales, que no tienen en cuenta su poder estructurante; referidos a productos de las disciplinas que todos los alumnos deben aprender. Nivel 2Ainstruccional/cientificista, en el cual siguen predominando los aspectos conceptuales, pero tiene en cuenta los procedimentales. Nivel 2B -espontaneísta, contempla los contenidos actitudinales y procedimentales. Nivel 3, integrador/transformador, integra los contenidos conceptuales, procedimentales y actitudinales. Desde estos niveles abordamos las categorías de interés, según Martínez (2000), (Martínez y Valbuena, 2013).

\section{Metodología}

Los resultados parciales que presentamos, corresponden a la segunda etapa de revisión de antecedentes, a partir de la caracterización de 10 ponencias seleccionadas, de las 235 presentadas en el $\vee$ Congreso Internacional sobre Formación de Profesores(as) en Ciencias, (Bogotá, Colombia) (Parga, 2011); según las categorías de investigación, a saber: contenidos escolares; fuentes y criterios de selección de los contenidos escolares; referentes del conocimiento escolar; y criterios de validez. Ponencias consideradas con base en el análisis de contenido, y con el apoyo del software Atlasti.

\section{Resultados}

En relación con las categorías de interés, podemos señalar: 
Revista Tecné, Episteme y Didaxis: TED. Año 2014, Número Extraordinario. ISSN Impreso: 0121-3814, ISSN web: 2323-0126

Memorias, Sexto Congreso Internacional sobre Formación de Profesores de Ciencias. 08 al 10 de octubre de 2014, Bogotá

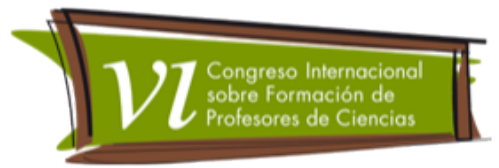

- Contenidos escolares: identificamos la preocupación por fundamentar el proceso de organización y complejización, así como la inclusión de diferentes tipos de contenidos. Algunos ejemplos son: las propuestas de trama didáctica de contenido TDC sobre el concepto de combustión, que favorecen las actitudes hacia la ciencia en los niños, con resultados que muestran un cambio gradual en éstas (Giraldo, López y Martínez, 2011); la organización de diferentes niveles de formulación -en este caso frente a la discontinuidad de la materia-, y la tipificación del proceso de complejización de las ideas de los estudiantes desde un "atomismo ingenuo" llegando a diferenciar entre sustancias puras y mezclas (Villamizar y Parga, 2011); y la organización de una progresión de aprendizaje en tres niveles -en torno al modelo de ser vivo- que les permite señalar que la mayoría de los estudiantes están en el nivel 2, en el que no se identifica la presencia de ser vivo (Mayerhofer y Márquez, 2011).

- Fuentes y criterios de selección de los contenidos escolares: se hace explícita la consideración de diferentes fuentes como: los lineamientos curriculares oficiales y los resultados de investigación (Villamizar y Parga, 2011); la discusión entre pares que contribuye a la evolución de los modelos inicialmente identificados (Mayerhofer y Márquez, 2011); y los textos escolares (Daza, Arrieta, Ríos y Rojas, $2011)$.

- Referentes epistemológicos del conocimiento escolar: reconocemos una posible tensión, entre la prelación del referente científico, y la consideración de otros referentes epistemológicos del conocimiento del profesor(a) y del conocimiento escolar, por ejemplo: en la investigación en torno a las concepciones de los profesores(as) sobre la naturaleza de la ciencia, en la que inicialmente los profesores(as) asumen una "visión ingenua", posteriormente se observan cambios, a una visión de la naturaleza de la ciencia denominada de "transición", o a una visión "informada" (Cofré, Jiménez, Santibáñez, Yacovic y Vergara, 2011); si bien se alude a la identificación de nociones contradictorias en los profesores(as), y al referente normativo, parece que el referente central es el científico. También se nota la relevancia del referente científico -en la posibilidad de que los textos escolares pueden introducir conceptos sobre la ciencia, alejados de aquellos que valida la comunidad científica-, a la vez se plantea la inclusión de otros referentes (didáctico, interdisciplinar), en el análisis del concepto de célula, en los libros de texto de educación primaria (Daza y otros, 2011). Resaltamos que de manera explícita se consideran otros referentes epistemológicos (el conocimiento histórico-epistemológico, el disciplinar, el psicopedagógico y el conocimiento del contexto escolar), a través de las TDC (Giraldo y otros, 2011). 
Revista Tecné, Episteme y Didaxis: TED. Año 2014, Número Extraordinario. ISSN Impreso: 0121-3814, ISSN web: 2323-0126

Memorias, Sexto Congreso Internacional sobre Formación de Profesores de Ciencias. 08 al 10 de octubre de 2014, Bogotá

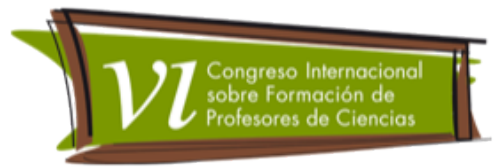

Destacamos el papel del conocimiento profesional del profesor(a) como referente explícito del conocimiento escolar, por ejemplo respecto a la argumentación, en particular las concepciones que sobre ésta tienen los profesores(as) y su inclusión como contenido de enseñanza (Ruiz, Márquez, y Tamayo, 2011). Igualmente en los procesos de formación de los docentes, en donde en la revisión de investigaciones en la formación inicial de profesores(as) que enseñan ciencias en primaria, se resalta la necesidad de construir el conocimiento didáctico del contenido, en las propuestas de formación de educadores infantiles (Vallejo, Obregoso y Valbuena, 2011).

- Criterios de validez del conocimiento escolar: Son escasas las investigaciones que dan cuenta de esta categoría, las cuales caracterizan la complejidad de diferentes pautas de validez, que se ilustran en tres casos analizados. En uno identifican criterios de validez relacionados con la autoridad de la maestra, la evidencia empírica y el texto escolar; en otro, señalan tensiones, por ejemplo, aunque el niño aporte un conocimiento "válido", de todos modos se debe llegar al "conocimiento científico"; y en el otro caso, no hay una verdad predefinida, sino que lo "mejor" lo define el grupo con la orientación del profesor(a) (Martínez y Rivero, 2011). Por otra parte se señala la emergencia de una concepción de argumentación, como herramienta de aprendizaje que permita evaluar al conocimiento (Ruiz et al., 2011).

Además de los criterios ya señalados, la revisión evidencia el interés de algunos investigadores alrededor de la construcción de un marco conceptual frente al conocimiento profesional del profesor(a) y al conocimiento escolar. $Y$ se indica que el conocimiento de los profesores(as), sobre el conocimiento escolar, asume diversos niveles de complejidad, que determinan tanto la selección de contenidos, como los criterios de validez, entre otros aspectos. Dichos niveles comprenden: una perspectiva tradicional; dos posibles transiciones, bien por la vía instruccional-cientificista o por la vía espontaneísta; y una tendencia transformadora-integradora (Martínez, Molina, Reyes, Valbuena y Hederich, 2011). En esta perspectiva de niveles de complejidad, se da cuenta de las pautas de validez del conocimiento escolar, organizadas en secuencias que van desde la autoridad incuestionable de la maestra y del conocimiento teórico; hasta el reconocimiento del rol protagónico de los estudiantes; que llevan a la maestra a preocuparse más por favorecer el debate y la búsqueda de consensos entre iguales (Martínez y Rivero, 2011 ). Por otra parte se hace una propuesta de Tramas Didácticas de Contenido, que integran diferentes contenidos y referentes (Giraldo y otros, 2011); y se construye un perfil del conocimiento del profesor(a) de 
Revista Tecné, Episteme y Didaxis: TED. Año 2014, Número Extraordinario. ISSN Impreso: 0121-3814, ISSN web: 2323-0126

Memorias, Sexto Congreso Internacional sobre Formación de Profesores de Ciencias. 08 al 10 de octubre de 2014, Bogotá

ciencias en primaria a través de un estudio de caso, en el que se hace seguimiento al desarrollo de una unidad didáctica sobre el ciclo del agua; acciones que realzan la importancia de este "conocimiento específico para la enseñanza de las ciencias" (Castaño y Aguaded, 2011).

\section{Conclusiones}

Los resultados de la presente revisión nos indican que aún son escasas las investigaciones en torno al conocimiento profesional de los profesores(as) de ciencias y el conocimiento escolar en primaria (Martínez y Valbuena, 2013). Las ponencias citadas, señalan la preocupación por dar cuenta de la epistemología escolar particular, así como por el reconocimiento de la complejidad de este conocimiento evidenciado a través de hipótesis de progresión, de tramas didácticas, niveles de formulación y niveles de aprendizaje, entre otros. Destacamos la investigación en torno a los contenidos escolares, en tanto se asume de manera intencional y fundamentada la importancia de la diversidad de contenidos y su organización. Algunas investigaciones se centran en el referente epistemológico propio de las ciencias, pero otras resaltan de manera explícita la inclusión de otros referentes. Consideramos que es fundamental hacer explícita la naturaleza particular del conocimiento profesional del profesor(a) de ciencias de primaria y del conocimiento escolar, para lo cual se requieren más investigaciones que contribuyan a dar cuenta de este propósito.

\section{Referencias bibliográficas}

Castaño S. y Aguaded S. (2011). El conocimiento del profesor en ciencias naturales para la enseñanza del agua en educación primaria: un estudio de caso. TED: Tecné, Episteme y Didaxis Nºxtraordinario, (págs.1700-1704).

Cofré, H., Jiménez, J., Santibáñez, D., Yacovic, M. y Vergara, C. (2011). Concepciones acerca de la naturaleza de la ciencia de profesores primarios en Chile: zes posible mejorarlas? TED: Tecné, Episteme y Didaxis NExtraordinario, (págs.1653-1659).

Daza, S., Arrieta, J., Ríos, O., y Rojas, R. (2011). El concepto de célula en los libros de texto de primaria, en contraste con lo presentado en la literatura científica. TED: Tecné, Episteme y Didaxis Nºxtraordinario, (págs. 1742-1748). 
Revista Tecné, Episteme y Didaxis: TED. Año 2014, Número Extraordinario. ISSN Impreso: 0121-3814, ISSN web: 2323-0126

Memorias, Sexto Congreso Internacional sobre Formación de Profesores de Ciencias. 08 al 10 de octubre de 2014, Bogotá

Giraldo, L., López, J., y Martínez., L. (2011). Dimensión actitudinal de las tramas didácticas del contenido. TED: Tecné, Episteme y Didaxis N Extraordinario, (págs. 1732-1736).

Martínez, C. (2000). Las propuestas curriculares sobre el conocimiento escolar en el área de conocimiento del medio: dos estudios de caso en profesores de primaria. Tesis Doctoral. Programa Didáctica de las Ciencias Experimentales y Sociales, un enfoque interdisciplinar. Universidad de Sevilla.

Martínez, C. y Jirón, M. (2012). La investigación sobre el conocimiento profesional de los profesores de primaria en ciencias: una revisión. Revista EDUCYT. Vol 6, Junio-Diciembre, (págs.68-87).

Martínez, C., Molina, A., Reyes, D. Valbuena, E., y Hederich, C. (2011). Una hipótesis de progresión del conocimiento del profesor de ciencias sobre el conocimiento escolar. TED: Tecné Episteme y Didaxis, 25, págs. 1589-1594.

Martínez, C., y Rivero, A. (2011). Criterios de validez del conocimiento escolar en las clases de ciencias en primaria: una mirada desde el conocimiento del profesor. TED: Tecné, Episteme y Didaxis N Extraordinario, (págs.1583-1588).

Martínez, C. y Valbuena, E. (comps) (2013). El conocimiento profesional de los profesores de ciencias sobre el conocimiento escolar. Resultados de Investigación. Bogotá: Universidad Distrital Francisco José de Caldas.

Mayerhofer, N., y Márquez, C. (2011). Influencia de la discusión entre iguales en la representación inicial del modelo ser vivo. TED: Tecné, Episteme y Didaxis $N^{\circ}$ Extraordinario, (págs. 1762-1766).

Parga, D. (2011). Presentación Quinto Congreso Internacional sobre Formación de Profesores de Ciencias. TED: Tecné, Episteme y Didaxis $N^{\circ}$ Extraordinario.págs.40-42.

Porlán, R. y Rivero, A. (1998). El conocimiento de los profesores. Sevilla: Díada Editora.

Ruiz, F., Márquez, C. y Tamayo, O. (2011). Evolución de los modelos de enseñanza de la argumentación en clase de ciencias en la Educación Primaria a 
Revista Tecné, Episteme y Didaxis: TED. Año 2014, Número Extraordinario. ISSN Impreso: 0121-3814, ISSN web: 2323-0126

Memorias, Sexto Congreso Internacional sobre Formación de Profesores de Ciencias. 08 al 10 de octubre de 2014, Bogotá

partir de un proceso de reflexión crítica. TED: Tecné, Episteme y Didaxis $N^{\circ}$ Extraordinario, (págs.1184-1188).

Vallejo Y., Obregoso A. y Valbuena E. (2011). Formación inicial de educadores infantiles que enseñan ciencias en básica primaria: una revisión documental. TED: Tecné, Episteme y Didaxis NExtraordinario, (págs.11581162).

Villamizar D. y Parga D. (2011). Complejización del conocimiento del estudiantado acerca de la discontinuidad de los materiales. TED: Tecné, Episteme y Didaxis N Extraordinario, (págs.1577-1582). 